\title{
An optimized upper divertor with divertor-coils to study enhanced divertor configurations in ASDEX Upgrade
}

\author{
A. Herrmann, M. Teschke, I. Zammuto, M. Faitsch, A. Kallenbach, K. Lackner, T. Lunt, R. Neu, \\ M. Rott, G. Schall, B. Sieglin, S. Vorbrugg, M. Weissgerber, M. Wischmeier, H. Zohm, and the \\ ASDEX Upgrade team
}

\author{
Max-Planck-Institut für Plasmaphysik, D-85748 Garching, Germany
}

\begin{abstract}
A new upper divertor with in-vessel coils to investigate 'advanced' magnetic configurations will be installed in ASDEX Upgrade. 'Advanced' magnetic configurations are part of a risk mitigation strategy should the conventional divertor configuration approach not be applicable for future fusion reactors. The concept of the new upper divertor, Div-IIo, consists of an outer divertor with embedded divertor coils, an inner divertor and a cryo pump with $15 \mathrm{~m}^{3} / \mathrm{s}$ effective pumping speed in the private flux region. The new divertor coils will be designed for $50 \mathrm{kAt}$ and can be operated with $5 \mathrm{~s}$ plateau phase. This paper presents the design concept of the divertor and coil support structure, the coils and the cryo pump. In addition the forces to the divertor structure due to normal operation and during disruptions are discussed.
\end{abstract}

Keywords: ASDEX Upgrade, Divertor, Tungsten, Diagnostics, Manipulator

\section{Introduction}

ASDEX Upgrade (AUG) came into operation in 1991. It was designed as a tokamak with reactor relevant shaping. The coil and control system allows to operate in lower single null (LSN), double null (DN) or upper single null (USN) with up to 1.6 MA plasma current and an initially open divertor configuration [1]. Divertor enhancements were concentrated on the lower divertor that was finally transferred to a solid tungsten divertor with vertical target plates and a large flexibility for magnetic configurations. Consequently, the physics program of AUG is concentrated on LSN magnetic configurations using this optimized lower divertor.

The controlled exhaust of power and particles from magnetically confined fusion plasma has been identified as one of the critical issues for the success of future fusion power plants. Advanced divertor geometries such as the Snowflake and Super-X configurations are alternatives to the conventional single null divertor configuration with solid $\mathrm{W}$-targets as foreseen for ITER. The investigation of such 'advanced' divertor configurations is part of a risk mitigation strategy should the conventional divertor configuration approach turn out not to be applicable to a future fusion reactor.

The extension of the AUG physics program towards the investigation of advanced divertor configurations requires a new divertor design, the installation of in-vessel coils and of a cryo pump. This modification will be done in the upper divertor, keeping the flexibility and the elaborate diagnostics for physics investigation in the lower divertor as in the past.

The conceptual design for the upper divertor structure with embedded divertor coils and cryo-pump is presented in section 2. In section 3 the forces acting to the new divertor and coil structure are presented.

59 The target shaping is discussed in section 4. A 60 summary is given in section 5 .

\section{2. Conceptual design of the upper divertor}

This paper presents the technical concept for the physics driven modification of the upper divertor. The rational for 'advanced' divertor configurations, the set of magnetic configurations, as well as a discussion on target shaping is presented in an own paper [2].

The technical requirements for the divertor design are identified by an iteration process between modelling of 'advanced' divertor configurations [2] and the requirements of LSN magnetic configurations (Fig. 1), as well as technical constrains.

The requirements identified for the new upper divertor Div-IIo are:

1. Two divertor coils with up to $50 \mathrm{kAt}$ each, allowing to access 'advanced' divertor configurations. The coils are separated by about $100 \mathrm{~mm}$. The distance between coils and target surface should be minimized.

2. The coils are operated in both polarities, but with currents in the opposite directions. Parallel and antiparallel current feeding should be investigated as option.

3. Existing reference discharges in LSN configuration should be compatible with the new structure of the upper divertor.

4. Pumping speed of at least $S_{\text {eff }}=15 \mathrm{~m}^{3} / \mathrm{s}$ in the private flux region to ensure a pumping capability comparable to the existing cryo pump in the lower divertor.

5. Hardening of the upper divertor target structure to cope with the high heating power of AUG for both helicities. This will be achieved by maximizing the target size, minimizing gaps in between targets and moderate shaping at the edges to avoid an overheating near to the gaps. 
6. The accessibility to the divertor region through upper ports for diagnostics should be maximized.

\subsection{Target and coil support structure}

The present design of the upper divertor is optimized for a large plasma volume and there is no available space behind the existing divertor to install the coils and a cryo pump. Consequently the existing divertor structure will be replaced by a new one. The plasma facing surface will be moved downwards to allow the installation of the coils. However, this is limited to $\Delta \mathrm{z}=-100 \mathrm{~mm}$ to be compatible with the LSN reference magnetic configuration as shown in Fig. 1. The coil and the divertor structure are combined in the outer divertor to minimize the required space. The water cooled divertor support structure acts as the cover plate for the coil casing (see Fig. 2). Following the ASDEX Upgrade vessel structure - 16 coil and divertor support structures will be installed into the 16 sections of AUG.

Electrically, ASDEX Upgrade consists of 8 octants connected by a thin $1,2 \mathrm{~mm}$ thick stainless steel bellow needed for the vacuum tightness. This way the toroidal resistance of the AUG vessel is high enough to allow a safe discharge break down. Following this concept, there is no electrical shortcut over octants by in- or exvessel components. This has to be considered also for the coil support structure that has to be a stiff toroidal ring. To avoid a toroidal short cut, the 16 segments of the coil support structure will be bolted together with screws and isolating $\mathrm{SiN}$ ceramic pads.

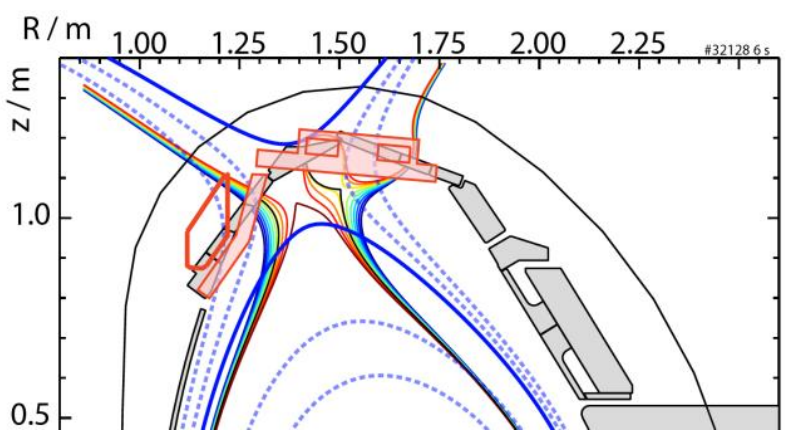

Fig. 1 Upper part of AUG with old (gray) and new Div-IIo (light red) divertor structure including cryo-pump. The LSN reference magnetic configuration is shown in blue. An advanced snow flake configuration is shown colored.

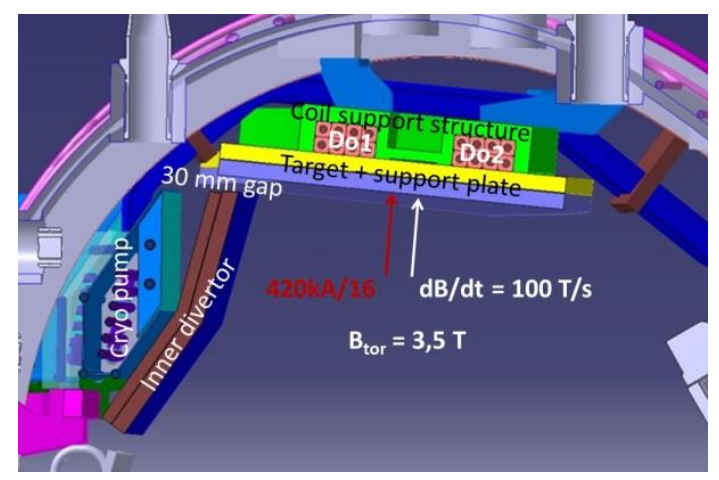

Fig. 2 CAD view of the new Div-IIo,.

\subsection{Divertor coils}

The 'advanced' divertor configurations require a maximum coil current of $50 \mathrm{kAt}$ with a coil separation of about $100 \mathrm{~mm}$. The coil will be operated in a quasi DC mode with a current ramp rate of max. $15 \mathrm{kA} / \mathrm{s}$.

There exist different concepts and technical solutions for in-vessel coils. In the conceptual design phase we are considering 3 coil concepts.

The AUG A-coil conductor that was qualified with the company HABIA Cables [3]. The conductor is a copper tube with a bore for the water cooling isolated by extruded PEEK.

Two coil concepts with a water cooled copper conductor inside a shielding tube. The isolation between the shielding tube and the copper conductor is realised by magnesium oxide as for the ITER in vessel coils $[4,5]$, silicon, or polyamide as for the DIII-D invessel coils [6]. In these concepts, the shielding tube acts as vacuum barrier.

AUG is operated with pulse lengths of max. $10 \mathrm{~s}$, i.e. there is no need for an active cooling that would provide constant coil temperature during the discharge. Instead the same concept as for all AUG in-vessel components will be applied: Adiabatic heating during the pulse and recooling afterwards with a typical cool down time of a few minutes.

The maximum temperature rise of the divertor coil at the end of a $5 \mathrm{~s}$ long current plateau with $50 \mathrm{kAt}$ is set to $\Delta \mathrm{T}=50 \mathrm{~K}$ for the parameter definition. Using $\mathrm{Cu}$ as conductor material this defines the maximum current density of about $45 \mathrm{~A} / \mathrm{mm}^{2}$, i.e between $3 \mathrm{kA}$ and 10 $\mathrm{kA}$ coil current for the A-coil and the shielded coil concept, respectively. Correspondingly, the number of turns/coil becomes $18(3 \times 6)$ and 5, respectively.

The temperature increase of $\Delta \mathrm{T}=50 \mathrm{~K}$ of the copper conductor will result in a certain stress. A detailed FEM calculation will be done for the final coil design. Nevertheless first estimations can be done assuming that the temperature difference between the copper and the stiff surrounding is $\Delta \mathrm{T}=50 \mathrm{~K}$. The pressure acting on the copper conductor follows to: $\frac{F}{A}=\frac{\Delta L}{L} E=\alpha \Delta T E(M P a) \approx 90$ or about or about $80 \%$ of the yield strength of copper. Here, E is Young's modulus and $\alpha$ the thermal expansion coefficient.

During the baking the temperature difference between components is below $\Delta \mathrm{T}=10 \mathrm{~K}$ due to the slow temperature increase. Stress is induced due to the slightly different thermal expansion coefficient of copper and stainless steel of about (10\%). Due to the moderate baking temperature of $150^{\circ} \mathrm{C}$ at ASDEX Upgrade the resulting stress will be lower than during coil operation.

The final design on the applied coil concept will be taken after prototype tests that are ongoing. Main criteria are the electric strength and the handling, inside the torus, in particular the bending.

\subsection{Cryo pump}

A physics program with USN magnetic configurations requires a pumping in the upper divertor 
region to control the neutral pressure. Consequently, a cryo pump will be installed together with the new divertor structure. The cryo pump in the lower divertor $[7,8]$ has a pumping speed of $100 \mathrm{~m}^{3} / \mathrm{s}$. It is placed at major radius of $\mathrm{R}=2.2 \mathrm{~m}$ and is toroidally distributed over about $70 \%$ of the toroidal circumference. The effective pumping area is given by the $2.45 \mathrm{~m}^{2}$ of the chevron at liquid nitrogen temperature and $2.0 \mathrm{~m}^{2}$ at liquid He temperature (about $4 \mathrm{~K}$ ), see Fig. 3. In the upper divertor the cryo pump is placed behind the inner divertor at about $\mathrm{R}=1.2 \mathrm{~m}$ and the effective pumping area is reduced. As a consequence the pumping speed is lower, $S_{p}=50 \mathrm{~m}^{3} / \mathrm{s}$. To guarantee an effective pumping speed of $S_{\text {eff }}=15 \mathrm{~m}^{3} / \mathrm{s}$ at the plasma the conductance between cryo pump and private flux region in the upper divertor has to be higher than $25 \mathrm{~m}^{3} / \mathrm{s}$. This is realized by the present design. It foresees a $30 \mathrm{~mm}$ wide slit between the outer and the inner divertor plate and the resulting conductance for deuterium is $65 \mathrm{~m}^{3} / \mathrm{s}$, well above the required value and would result in an effective pumping speed in the private flux region of $\mathrm{S}_{\mathrm{eff}}=28 \mathrm{~m}^{3} / \mathrm{s}$.

The AUG cryo pump is operate with saturated liquid helium. The capacity of the existing He-liquefier $(18 \mathrm{~kg} / \mathrm{h})$ can supply the existing lower $(4 \mathrm{~g} / \mathrm{s})$ and the new upper cryo pump ( $3 \mathrm{~g} / \mathrm{s})$.

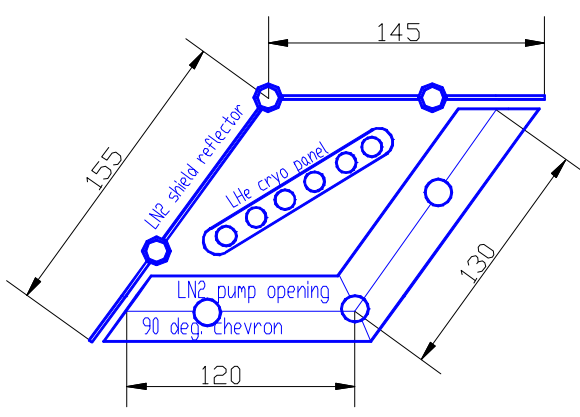

Fig. 3 Cross section of the existing AUG cryo-pump.

\section{Forces}

The AUG vacuum vessel is suspended by 8 rods. These suspension rods are fixed at the support structure of the toroidal field coils. The total weight of the vacuum vessel is about $650 \mathrm{kN}$, being about half of the totally allowed load to the suspension rods of about $1300 \mathrm{kN}$. During disruptions, an additional load up to $450 \mathrm{kN}$ was measured with strain gauges.

Access to the vacuum is possible by $2 \times 3$ small vacuum ports (max. $63 \mathrm{~mm}$ diameter) pointing up and down, respectively and two $280 \mathrm{~mm}$ dia. horizontal ports in each of the 16 sectors. In addition there are 8 A-ports and $2 \times 8280 \mathrm{~mm}$ dia. B-ports alternating between the sectors in the midplane, see Fig. 4.

Due to the restricted access through the ports the divertor coils have to be fixed inside the vacuum vessel and the interaction force between divertor coils and external coils has to be taken by the vessel and the suspension rods. In the following, first the static forces acting in between coils are estimated followed by a disruption analysis.

\section{3.1. Static forces}

The poloidal field coils are supported by an external support structure independently from the toroidal field structure and the vacuum vessel. The coils and their arrangement around the vacuum vessel are indicated in Fig. 4.

For an estimation of the static forces onto the vessel itself and the suspension rods the worst case of maximum currents through the divertor coils and the poloidal field coils will be discussed. In reality, the supply current is by about a factor of two lower due to limitations of the power supply units. For the case that both divertor coil currents have the same polarity (parallel feeding) the resulting force on the divertor coils is $>640 \mathrm{kN}$. This force is in the order of the vessel weight of $650 \mathrm{kN}$. Parallel feeding would lift up the vessel or double the weight depending on the polarity. This brings us to the conclusion that the parallel feeding should not be considered as realistic option with the present support structure of the vacuum vessel.

The net force to the coil package is reduced for anti-parallel feeding to about $12 \mathrm{kN}$ without plasma current and is about $16 \mathrm{kN}$ with the maximum applied plasma current of $I_{p}=1.4$ MA. This force is below 3\% of the vessel weight and can be taken by the suspension rods. Nevertheless, on a single coil the total force of $\pm 640 \mathrm{kN}$ is applied and a torque remains due to the finite distance between the coils of about $100 \mathrm{~mm}$. This torque and the force between the coils of about $30 \mathrm{kN}$ has to be taken by the coil support structure.

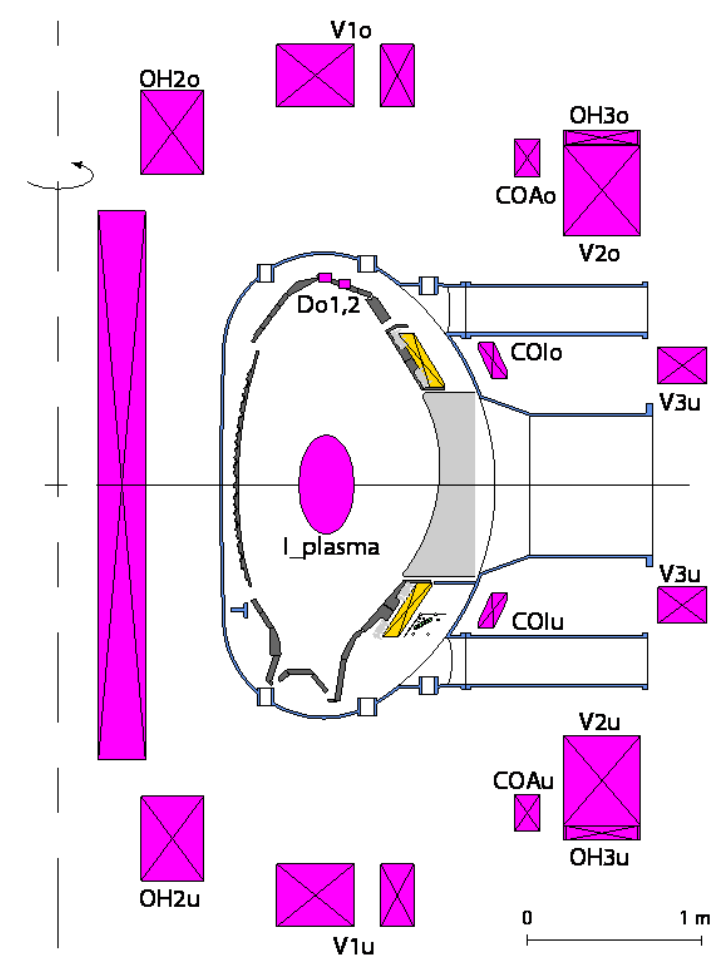

Fig. 4 Cross section of AUG vessel and positions of the divertor and poloidal field coils

In order to achieve the desired advanced divertor configurations, an imbalance of the coil currents is required to realize the envisaged magnetic 
configurations. The case with $-52 \mathrm{kAt}$ and $41 \mathrm{kAt}$ current in the divertor coils for a realistic plasma configuration with $I_{p}=1$ MA was calculated with ANSYS-FEM. The resulting interaction force to the coil is about $17 \mathrm{kN}$, i.e. equivalent to the worst case force estimation for anti-parallel feeding and maximal current in the poloidal field coils. The magnetic configurations used in the modeling to define the physics goals can be realized technically in ASDEX Upgrade.

\subsection{Disruption forces}

Disruptions are a main concern for safe machine and diagnostic operation. For the new upper divertor, Div-IIo, we will consider:

- Halo currents flowing through the structure towards the vessel.

- Eddy currents induced in the support and divertor structure.

- Voltage and currents induced in the divertor coil.

During disruptions, voltages will be induced in the support structure and the coils. The coil support structure is divided in 16 sub segments which are isolated from each other. It could be segmented further to reduce eddy and halo currents to a limit tolerable for the mechanical structure. For the force estimation it is assumed that $30 \%$ of the plasma current, $\mathrm{I}_{\mathrm{p}}=1.4 \mathrm{MA}$, is flowing into the upper divertor structure (Fig. 2). This results in about $26 \mathrm{kA} /$ module and about $10 \mathrm{kN}$ force at each of the 4 fixing points in case of the maximum toroidal field strength of $\mathrm{B}_{\mathrm{t}}=3.5 \mathrm{~T}$.

The coil and the divertor support structure have typical dimensions of about $300 \times 600 \mathrm{~mm}^{2}$ and $400 \times 600 \mathrm{~mm}^{2}$, respectively. For stainless steel and a $\mathrm{dB} / \mathrm{dt}=100 \mathrm{~T} / \mathrm{s}$ the induced torque is $13 \mathrm{kNm}$ and $22 \mathrm{kNm}$, respectively. For a single module the torque has to be taken by the support at the vessel. With the present coil and divertor concept the single modules are mechanically connected to a stiff toroidal ring and the force of about $100 \mathrm{kN}$ resulting from the torque is balanced at the interface between the modules. The electric insulation in between modules is realized by SiN ceramics that can withstand the high loads.

A main concern of the design is the voltage induced into the upper coil during disruptions. Due to the large area, the induced voltage, $U_{\text {ind }}=-N A \frac{d B}{d t}$, is $5.4 \mathrm{kV}$ and $6.7 \mathrm{kV}$ for the inner and outer coil, respectively. For force reasons the coils have to be operated antiparallel. This will be hardwired (Fig. 5) so the induced voltage at the coil current feed through is reduced to tolerable $1.3 \mathrm{kV}$. Nevertheless, this high voltage can drive a current that is $10-20$ times larger than the nominal coil current, in case of a low external resistance as the power supply is. To avoid such a strong current and the resulting forces during a disruption, lasting about $10 \mathrm{~ms}$, additional coils limiting the current increase, $\mathrm{dI} / \mathrm{dt}$, are added inbetween the divertor coils and the power supply. They limit the current raise during a disruption to about $0.3 \mathrm{kA}$. As a further safety measure, pyro fuses can be installed to open the coil circuit. A fail-safe unbalancing of the coil current is needed to realize the required magnetic configurations. Therefore, an additional power supply with passive current limitation (output resistors) will be connected to the common junction of both divertor coils

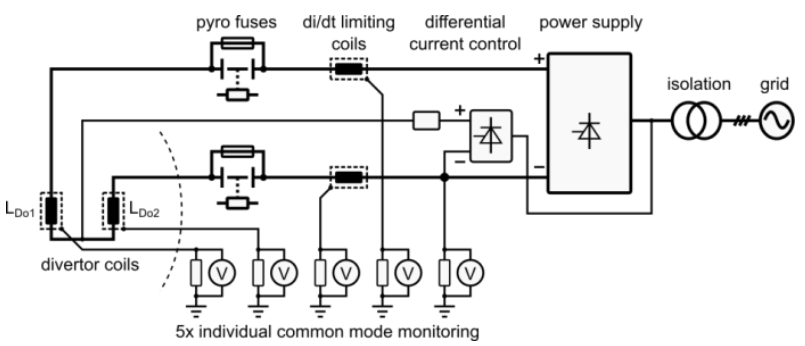

Fig. 5 Principal electrical scheme of the power supply and the safety elements.

Halo and eddy currents to the divertor and coil support structure are in the same order of magnitude as in other components of AUG and can be handled. Special attention is needed to realize passive safety for divertor coil operation.

\section{Target shaping}

The outer divertor structure will be a well aligned stiff ring because it acts also as coil casing. That's why there are no gaps and no steps between divertor sections. From this, there is no need for module and target tilting and flat divertor plates without tilting will be installed. This allows operating the divertor with both helicities of the magnetic field configurations. A sequence of LSN - DN - USN magnetic configuration can be run as in the past. By reversing the direction of the toroidal magnetic field (helicity) upper USN magnetic configurations can be operated with ion-grad $\mathrm{B}$ drift direction towards the divertor, which is found to provide favorable plasma properties.

Technically, the assembly tolerance will result in a step of $\pm 0,1 \mathrm{~mm}$ between adjacent target tiles. The toroidal gap size will be $<1 \mathrm{~mm}$. Leading edge effects are estimated with a simple geometric picture and 5 deg for the maximum pitch angle between the magnetic field line and the flat target surface. With these parameters the edge heat load is about 2.5 times the heat load at the flat part of the target. In reality the temperature increase will be lower due to the favourable heat transport into the target at the edges.

In addition, we have experimental experiences with flat targets and gaps of about $1 \mathrm{~mm}$ exposed in the lower divertor. The experimental results confirm that gaps below $1 \mathrm{~mm}$ did not result in overheated edges.

The clamping concept itself is not finalized yet because it depends on the target material which will be either tungsten/tungsten alloy or tungsten coated graphite. In any case, the clamping concept will allow mounting targets with arbitrary shape. 


\section{Summary and Conclusions}

The concept for a new upper divertor in ASDEX Upgrade with in-vessel coils to investigate 'advanced' magnetic configurations is presented. 'Advanced' magnetic configurations are part of a risk mitigation strategy should the conventional divertor configuration approach not be applicable for future fusion reactors. The new upper divertor, Div-IIo; consists of an outer divertor with embedded divertor coils, an inner divertor and a cryo pump with $15 \mathrm{~m}^{3} / \mathrm{s}$ effective pumping speed in the private flux region. The new divertor coils will be design for $50 \mathrm{kAt}$ and can be operated for $5 \mathrm{~s}$ plateau phase. Halo and eddy currents flowing through the divertor and coil support structure are in the same order of magnitude as in other components of AUG and can be handled. Special attention is needed to realize passive safety for divertor coil operation. The flat arrangement of the target tiles allows operation with both helicities of the magnetic configuration.

\section{References}

[1] A. Herrmann, (Guest editor), Special Issue on ASDEX Upgrade, Fusion Science and Technology, 44 (2003) 1747.

[2] T. Lunt, A. Kallenbach, H. Zohm, A. Herrmann, M. Wischmeier, Y. Feng, A.U. team, Design of an alternative upper divertor in ASDEX Upgrade supported by EMC3-Eirene simulations, Nuclear Materials and Energy (PSI2016), submitted for publication (2016).

[3] I. Zammuto, M. Rott, B. Streibl, W. Suttrop, T. Vierle, Conceptual design of in vessel mid-plane saddle coils for fast AC operation in ASDEX Upgrade, Fusion Eng. Des., 86 (2011) 1067- 1071.

[4] M. Kalish, P. Heitzenroeder, A. Brooks, L. Bryant, J. Chrzanowski, E. Daly, R. Feder, J. Feng, M. Messineo, M. Gomez, C. Hause, T. Bohm, I. Griffiths, A. Lipski, M. Mardenfeld, M. Nakahira, C. Neumeyer, R. Pillsbury, M. Sawan, M. Schaffer, R. Simmons, P. Titus, I. Zatz, T. Meighan, Iter In-Vessel Coil design and R\&amp;D, in: 2011 IEEE/NPSS 24th Symposium on Fusion Engineering, 2011, pp. 1-6.

[5] A. Encheva, H.Omran, A.Devred, A.Vostner, N.Mitchell, F.L. CH.Jun, C.Zhou, B.Macklin, HP.Marti, C.Sborchia, A.DellaCorte, A.Dizenobio, A.Anemona, H.J. Y.Wu, A.Xu, J.Jin, Progress on the Design Development and Prototype Manufacturing of the ITER In-Vessel Coils, Fusion Eng. Des., SOFT 2016 (2016).

[6] P.M. Anderson, C.B. Baxi, A.G. Kellman, E.E. Reis, Design, fabrication, installation, testing and initial results of in-vessel control coils for DIII-D, in: 20th IEEE/NPSS Symposium onFusion Engineering, 2003., 2003, pp. 573-576.

[7] B. Streibl, S. Deschka, O. Gruber, B. Jüttner, P. Lang, K. Mattes, G. Pautasso, J. Perchermeier, K. Schippl, H. Schneider, U. Seidel, W. Suttrop, G. Teller, M. Weissgerber, In-Vessel Cryo Pump for ASDEX Upgrade Divertor II, in: C. Varandas, F. Serra (Eds.) Fusion Technology (Proc. of the 19th Symposium on Fusion Technology, Lisbon, 1997), Elsevier, Amsterdam, 1997, pp. 427-430.

[8] B. Streibl, A. Kaltenberger, H. Kollotzek, K. Mattes, V. Rohde, G. Schall, K. Schindler, Operational behaviour of the ASDEX upgrade in-vessel cryo pump, Fusion Eng. Des., 56-7 (2001) 867-872. 